\title{
Measurement of Variations in Atmospheric Refractive Index With an Airborne Microwave Refractometer ${ }^{1}$
}

\author{
Howard E. Bussey and George Birnbaum
}

\begin{abstract}
A microwave refractometer for aircraft use is described, and some of the sources of error in the measurement of variations of atmospheric refractive index with this instrument are discussed. Observations were made up to 10,000 feet on 2 days near Washington, D. C. Two refractive-index soundings taken $1 \frac{1}{2}$ hours apart showed changes that, in the coarser aspects, resembled changes shown by radiosonde data. The fluctuation intensity changed erratically with time and place, but was usually greatest where the vertical gradient was changing. A rough analysis of the data showed that the larger fluctuations occurred over distances of several hundred meters, whereas over distances less than 5 meters the fluctuations were negligible (the response of the instrument would have allowed the detection of fluctuations occurring within 0.5 meter). Large increases in index were observed on entering cumulus clouds and intense fluctuations were noted within the clouds.
\end{abstract}

\section{Introduction}

Experience shows that meter- and centimeterlength electromagnetic waves are propagated far beyond the horizon $[1,1 \mathrm{a}]{ }^{2}$ with a field strength much greater than what can be accounted for on the basis of standard diffraction theory [2]. To explain this discrepancy it has been proposed that the waves are scattered by inhomogeneities in the refractive index of the atmosphere. ${ }^{3}$ Consequently, there is need for a detailed knowledge of the refractive-index structure of the atmosphere, especially with regard to sharp changes in the vertical gradient and irregular local variations from the mean value. Apart from these considerations, observations of refractive-index variations in the upper atmosphere are of interest in their own right in meteorological science, especially because of their close relation to the water-vapor structure there.

Many observations of atmospheric refractive index have been made recently with an airborne microwave refractometer by Crain and coworkers [4]. A few observations with an airborne microwave refractometer of somewhat different design are reported here. Except for modifications necessitated by aircraft installation, this instrument was essentially that developed by Birnbaum [5] and used for observations near the ground $[6,7]$. Special attention was given to the problem of measuring rapid fluctuations as there is virtually no information available on refractive-index inhomogeneities of small extent.

This paper describes the essential features of the airborne instrument and its performance, exhibits selected portions of the data obtained on a flight up to $10,000 \mathrm{ft}$ and through clouds, presents the results of a crude statistical treatment of the data, and discusses the experiment in relation to previous meteorological measurements.

Parts of this paper were presented at the Third Radar-Weather Conference. McGill University, Montreal, Canada, Sept. 1952, and at the Joint Meeting of URSI and IRE, Washington, D. C., April 1953.

2 Figures in brackets refer to literature references at the end of this paper.

3 A review of radio-wave scattering by the atmosphere nas been published by Megaw [3].

\section{Description of Equipment}

The frequency change, $\Delta f$, of a cavity resonator due to a refractive-index change, $\Delta n$, of the air contained therein is expressed to a very good approximation by

$$
-\Delta f / f=\Delta n \text {. }
$$

As in this work $\Delta n$ is of the order of $10^{-6}$, it is convenient to introduce a quantity $\Delta N$ defined by

$$
\Delta N=\Delta n \times 10^{6},
$$

where $N$ is called an $N$-unit. $\Delta f$ is measured by electronically comparing the frequencies of a ventilated (test) cavity and a sealed (reference) cavity. These are excited by a frequency-modulated klystron, and their outputs after detection yield resonance curves that are used to control the width of a rectangular voltage waveform. This voltage is averaged, amplified, and recorded.

The design of the instrument constructed for aircraft operation differed somewhat from that described $[5,6]$ in previous reports. The klystron (type $2 \mathrm{~K} 25$ ) was isolated from the large pressure changes encountered in ascents and descents by sealing its mount. An available power supply originally designed for $60-\mathrm{c} / \mathrm{s}$ input voltage operated satisfactorily with the $800-\mathrm{c} / \mathrm{s}$ voltage supplied by the aircraft. The klystron sweep voltage was synchronized to the aircraft mains, and consequently, the time constants of the electronic circuits were adjusted for a pulse repetition rate of $800 \mathrm{c} / \mathrm{s}$.

The sampling cavity ${ }^{4}$ was installed at a location believed to be in free air, undisturbed by turbulence along the fuselage. It was attached on the end of a streamlined boom (fig. 1) $3.7 \mathrm{ft}$ long located $6.7 \mathrm{ft}$ from the nose of the aircraft (a Navy type P4Y2). The waveguide lead to the cavity was insidethe boom. The electronic circuits, reference cavity, and klystron located nearby were shock-mounted. As further protection from aircraft vibration, low micro-

\footnotetext{
4 This and the reference cavity operated in the $\mathrm{TE}_{011}$ mode at $9,000 \mathrm{Mc}$
} 

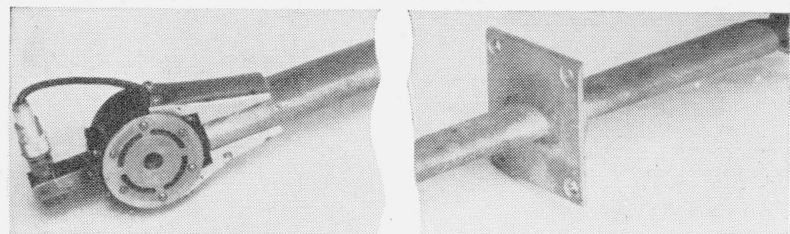

Figure 1. Sampling cavity attached to the end of the strut.

phonic tubes (12AY7) were employed in the input stages of the resonance pulse amplifiers. Connection between the shock-mounted waveguide and the rigidly mounted waveguide in the boom was effected by a short length of flexible coaxial cable.

The reference cavity was provided with a small diameter plunger driven by a micrometer whose scale was calibrated in terms of cavity frequency change. By means of this plunger the refractometer was calibrated, also the recording pen was reset whenever it approached the off-scale position. The latter adjustment permitted the use of a sensitive scale to determine fine detail, yet preserved the much larger changes in refractive index that occurred in a sounding.

Invar of high purity that had been subjected to a special heat treatment [8] was used in the construction of the test cavity in order to minimize thermal expansion. The treated metal had a measured coefficient of linear expansion of $0.3 \times 10^{-6} /{ }^{\circ}$ C., and the finished cavity had the same coefficient because the change in the refractometer reading due to heating of the cavity was $0.3 \mathrm{~N} /{ }^{\circ} \mathrm{C} .^{5}$ However, after installing the cavity in the aircraft the coefficient increased to $0.5 \times 10^{-6} /{ }^{\circ} \mathrm{C}$. It is felt that this was due to stressing by the aluminum supports. The reference cavity available from previous work was temperature compensated to within $0.5 \times 10^{-6} /{ }^{\circ} \mathrm{C}$ by using brass end plates suitably recessed into an untreated invar $\left(\alpha=3 \times 10^{-6}{ }^{\circ} \mathrm{C}\right)$ barrel.

Possible changes in air density arising from the rapid passage of air through the cavity were investigated at speeds up to $170 \mathrm{mph}$. The test cavity was mounted in the NBS wind tunnel and changes of air density in the cavity were deduced from measurements with the refractometer. Within the experimental error of 0.5 to $1 N$ caused by constant addition of fresh air to the tunnel, the densities of air within tunnel and cavity were alike.

The smoothing of air-temperature fluctuations due to contact of air with the cavity walls was determined in previous laboratory tests for air speeds up to 25 mph. At this speed the amplitude of air-temperature fluctuations was reduced by 20 percent; but at aircraft speeds the reduction should be negligible.

The ability of the refractometer to record rapid changes in index clearly depends on the repetition rate of the klystron sweep voltage. Thus for a sweep rate of $f$ (equal to $800 \mathrm{c} / \mathrm{s}$ in the present case), oscillations at a frequency of $f / 2$ should be detected and the shape of those at $f / 6$ or less should be well

\footnotetext{
$\Delta f / f=-\alpha$, where $\alpha$ is the linear-expansion coefficient.
}

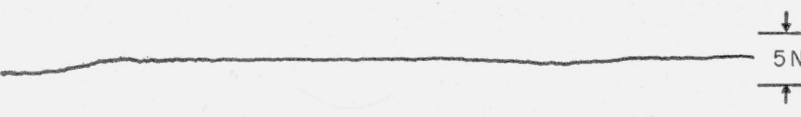

a
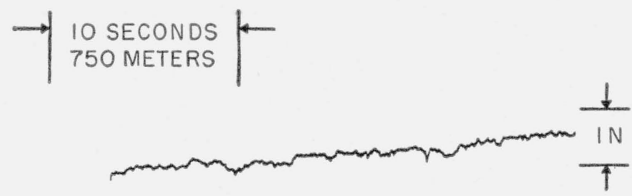

b

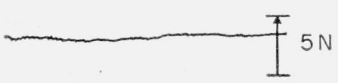

FIgURE 2. Two segments of the refractive-index record obtained while in level flight in very homogeneous air at about 10,000foot altitude.

reproduced. The response time of the present equipment, however, was found to be limited by that of the recording milliammeter. ${ }^{6}$ The response of the recorder was essentially flat out to $20 \mathrm{c} / \mathrm{s}$, and it decreased by a factor of one-half at $45 \mathrm{c} / \mathrm{s}$.

While making atmospheric observations a constant chart speed of $2.5 \mathrm{~mm} / \mathrm{sec}$ was used. Consequently, oscillations more rapid than $10 \mathrm{c} / \mathrm{s}$ would not be individually resolved. They would, however, broaden the trace if they were continuously present as the recorder could respond to higher frequencies. The trace width was normally $1 / 3 \mathrm{~mm}$, which was equivalent to $0.05 \mathrm{~N}$ on the most sensitive range used, $7 N$ full scale. On the basis that an 80-percent broadening of the trace was easily visible and taking account of the decrease in recorder response at higher frequencies, it was estimated that the minimum amplitude of index oscillation necessary for detection at various frequencies was as indicated in table 1.

TABLE 1.

\begin{tabular}{|c|c|c|}
\hline Frequency & $\begin{array}{c}\text { Minimum de- } \\
\text { tectable ampli- } \\
\text { tude }\end{array}$ & Length \\
\hline$c / s$ & $N$ & $m$ \\
10 & 0.02 & 4 \\
75 & .04 & 0.5 \\
375 & .5 & .1 \\
\hline
\end{tabular}

The length there is the distance traversed by the aircraft (whose speed was $75 \mathrm{~m} / \mathrm{sec}$ ) during a half cycle of the oscillation. It indicates the approximate "size" of the index inhomogeneity that would give rise to the frequency in question.

The smallest refractive-index fluctuation that can be reliably observed is limited by noise originating within the equipment. In the laboratory a maximum noise amplitude of $0.05 N$ was observed, and this occurred in intervals of the order of 1 to 2 sec. There were virtually no current variations visible in

${ }^{6}$ By strongly modulating the screen voltage of one of the amplifiers, the width of the refractometer rectangular pulse, and hence output current, was made to vary sinusoidally. 
$1 / 10$-sec intervals or shorter. In flight it was not convenient to seal the ventilated cavity in order to obtain a record of equipment noise. Instead, an upper limit of this noise was estimated by assuming that it alone was responsible for the variations in the smoothest section of the data. Figure 2 shows two such records obtained in very homogeneous air at $10,000 \mathrm{ft}$. The deviation from the mean in $1 / 4$-sec intervals was about $0.02 N$ and in 1-sec intervals about $0.07 \mathrm{~N}$.

No effort was made to determine the longtime stability of the equipment. This depends in large measure, however, on the thermal expansion of the cavities as the temperature environment changes. The observed temperature change in the ascent to $10,000 \mathrm{ft}$ was large enough to give an indicated change of several $N$-units. Some variation might occur also from drift in klystron center frequency with temperature, as the klystron was not thermostatically controlled. In addition, pressure changes during ascent might shift the frequency of the sealed cavity slightly. Although these effects could cause errors of perhaps 5 percent in the sounding, they do not influence the reliability of the observations of fluctuations.

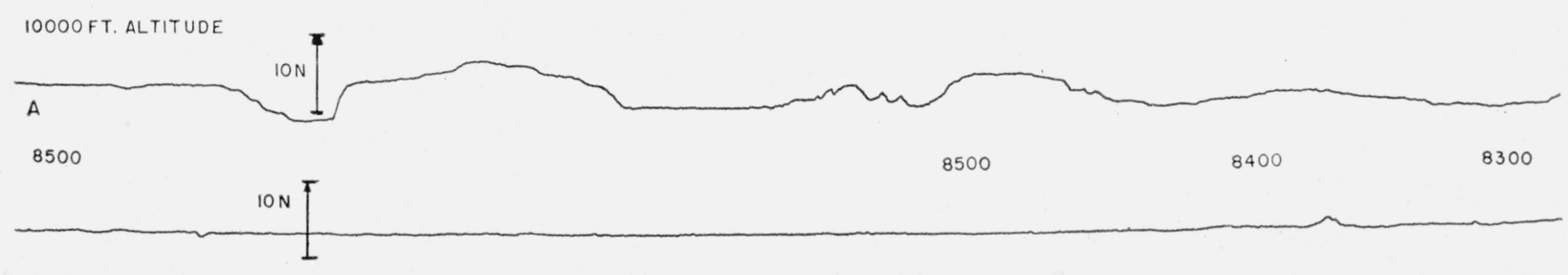

B
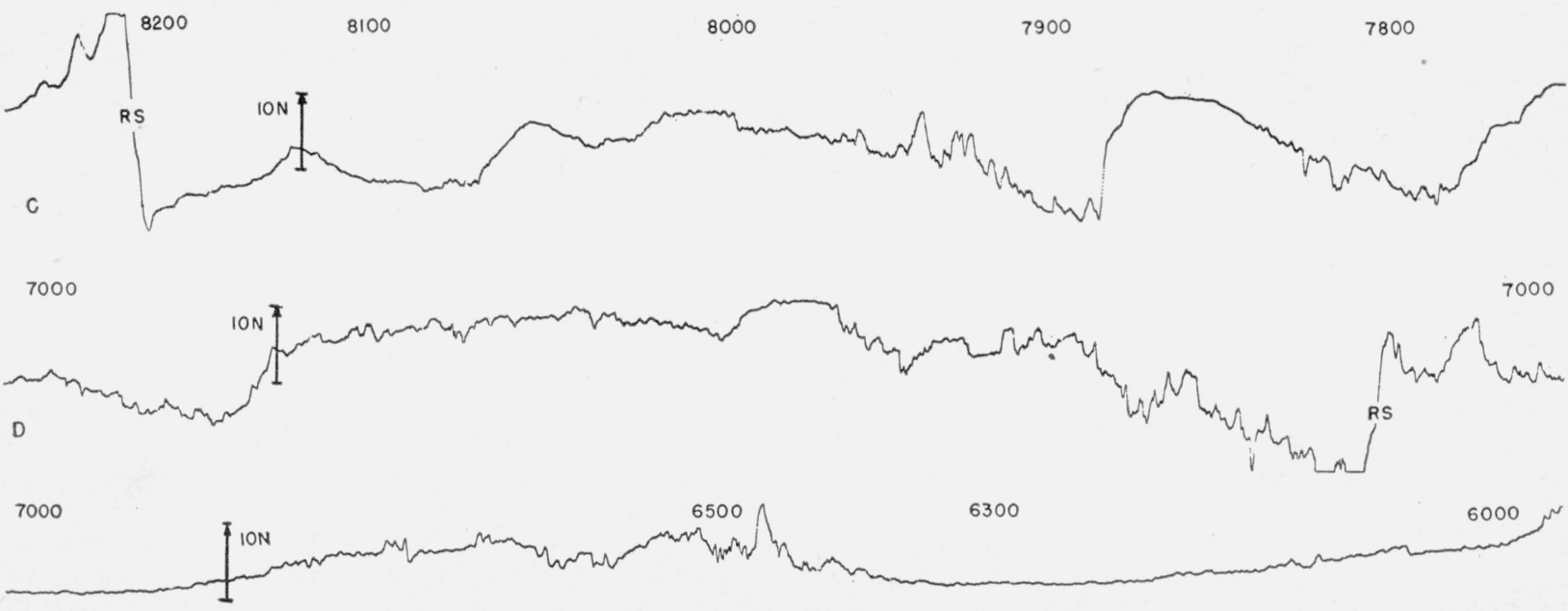

E

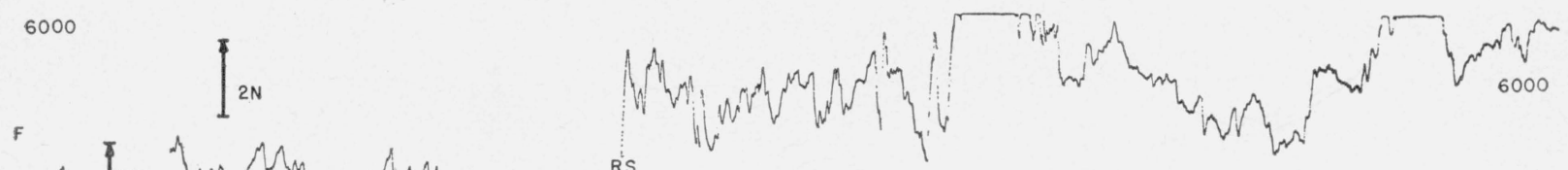

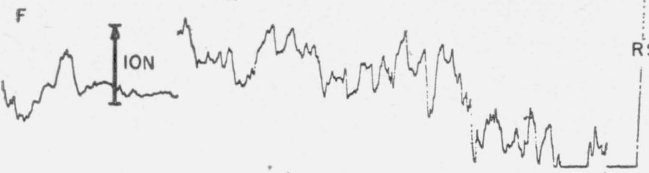

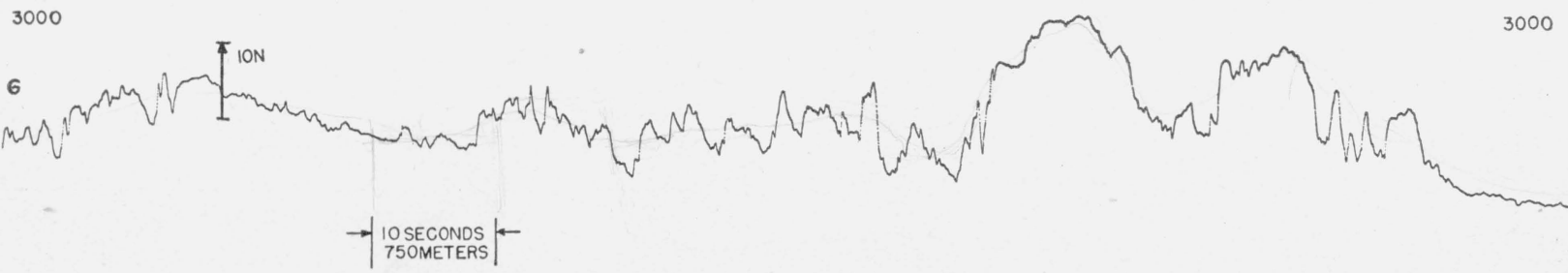

Figure 3. Examples of refractive-index data.

The length of each strip represents the passage of 126 seconds in time or about 10 kilometers in distance. 


\section{Results}

The observations described in this section were obtained over the Chesapeake Bay within 12 miles of North Beach, Md., on August 19, 1952, from 1300 to $1600 \mathrm{EST}$. The weather was warm and humid. There was a 15-mph north wind up to about 8,000 $\mathrm{ft}$, and above this level there was a $25-\mathrm{mph}$ west wind. The radiosonde temperature profile indicated a dry adiabatic lapse rate (neutral equilibrium) up to $4,000 \mathrm{ft}$ and a moist adiabatic lapse rate above $4,000 \mathrm{ft}$. The presence of scattered cumulus clouds with bases at 4,000 ft and tops at 12,000 to $14,000 \mathrm{ft}$ was evidence of large-scale vertical convection processes.

\subsection{Description of Data}

The horizontal speed of the aircraft was kept to about $75 \mathrm{~m} / \mathrm{sec}(170 \mathrm{mph})$ and during a sounding the ascent or descent rate was held to about 2.5 $\mathrm{m} / \mathrm{sec}$. Thus the slope of the inclined path was about one-thirtieth. In figure 3 are shown sections of strip charts, each of which is $126 \mathrm{sec}$ in duration. During this time the aircraft traveled $10 \mathrm{~km}$ horizontally, and, if making a sounding, changed altitude by $300 \mathrm{~m}$.

Although the atmosphere at $10,000 \mathrm{ft}$ was for the most part smooth and homogeneous, as shown in figure 2 , there was a short time when it was not, as is illustrated in figure 3, a. This figure shows the occurrence of slow variations of appreciable amplitude, but with virtually none of the rapid fluctuations that were usually observed at lower levels.

Figure 3, b, illustrates the pronounced and widespread uniformity of refractive index that was encountered from 8,500 to $8,300 \mathrm{ft}$ (during the descent), and which persisted for the most part up to $10,000 \mathrm{ft}$ the highest altitude explored.

Figure 3, c, shows a very large increase in index, namely, $25 \mathrm{~N}$, between 8,300 and $8,100 \mathrm{ft}$. (The pen went off scale during this increase and was reset at the place marked RS.) This region of fast transition was caused by a widespread and persistent stratification of the atmosphere. It was observed during four ascents or descents within a half-hour period and was always encountered at the same height to within $\pm 100 \mathrm{ft}$. This apparent boundary between two air masses was visible as a sharply defined haze line, with comparatively clear air above. This would indicate, in agreement with the large variation of index, that the air was moist below the transition and dry above it.

Another striking feature of this record is the smooth and very rapid increase of $10 \mathrm{~N}$ at $7,900 \mathrm{ft}$. This increase, which represents one of the sharpest boundaries encountered, occurred within 0.7 sec, during which time the aircraft traveled $50 \mathrm{~m}$ horizontally and descended $2 \mathrm{~m}$. The index then slowly returned to about its former value in a horizontal distance of $2,500 \mathrm{~m}$.

At $7,000 \mathrm{ft}$ the plane was leveled for horizontal flight. Fluctuations of various durations and amplitudes occurred (fig. 3, d), but most interesting of all was a well-defined refractive-index variation that extended about 5 miles and had a mean amplitude of about $12 N$.

Figure 3, e, was obtained in descending from 7,000 to $6,000 \mathrm{ft}$.

An example of a record in which the full-scale sensitivity was changed from 33 to $7 N$ is shown in figure $3, \mathrm{f}$, although in general the index variations were too great to permit the use of the more sensitive scale. No perceptible broadening of the stylus trace occurred on changing sensitivity, indicating that continuous fluctuations with durations of 0.1 to 0.02 sec $(7.5$ to $1.5 \mathrm{~m})$ were of amplitude less than $0.03 N$. The smallest fluctuations that are plainly visible have amplitudes of 0.1 to $0.2 \mathrm{~N}$ and durations of 0.2 sec. There are many fluctuations of 1 to $2 N$ with durations of a few seconds.

At 3,000 ft the fluctuations (fig. 3, g) were definitely of greater amplitude than at the higher elevations. The strikingly large-amplitude and long-duration fluctuations near the end of the record are indicative of large and rather homogeneous eddies of air whose refractive index differs markedly from the mean. As will be indicated later, these variations as well as those of smaller amplitude arise chiefly from variations in vapor density.

\subsection{Refractive Index of Clouds}

Refractive-index observations were made at 7,000 ft while flying through some fair-weather cumulus clouds. These had bases at roughly $4,000 \mathrm{ft}$ and tops in the neighborhood of 12,000 to $14,000 \mathrm{ft}$. The air temperature inside and outside the cloud was approximately the same, $13.5^{\circ} \mathrm{C}$. On entering a rather well-developed cloud the refractive index increased by about $40 \mathrm{~N}$ and then fluctuated violently (fig. 4, a). The increase that can be seen in the figure amounts to $16 \mathrm{~N}$, but while the trace was off scale (marked A) the frequency of the reference cavity was changed by an amount equivalent to $30 \mathrm{~N}$ in an attempt to set the pen on scale. Then the

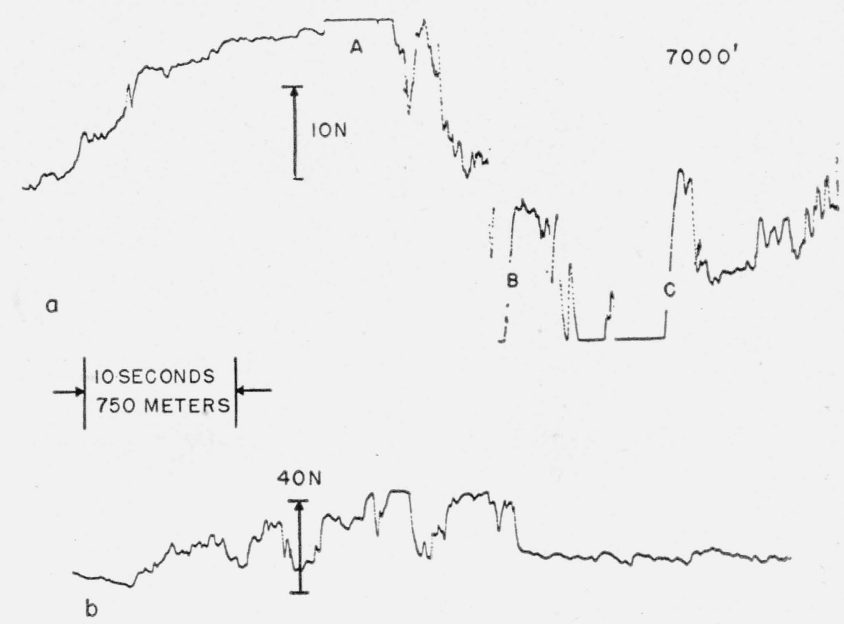

FIgURE 4. Records obtained on flying through fair-weather cumulus clouds. 
index suddenly decreased and went off scale as the most dense part of the cloud was passed. The trace was reset at points $\mathrm{B}$ and $\mathrm{C}$. By taking into account the displacements of the tuning plunger, it was seen that after leaving the cloud the refractive index returned to its original value. Changes of 6 to $10 \mathrm{~N}$ within a distance of about $25 \mathrm{~m}$ were observed in the cloud. Further evidence of the great turbulence that existed there were the bumps experienced by the aircraft. By way of contrast, it may be mentioned that a moderate bump was encountered in clear air with no noticeable change in index.

On entering another cloud not as well developed as the first, the index increased by $35 N$; and on leaving, decreased by this amount (fig. 4, b). In this case the full-scale sensitivity was $135 \mathrm{~N}$. Inside the cloud several changes as large as $20 \mathrm{~N}$ were noticed.

Remarkably sharp refractive-index gradients were observed in both clouds; changes of 12 to $15 \mathrm{~N}$ within a distance of $12 \mathrm{~m}$ occurred in three or four instances and of $6 \mathrm{~N}$ within $2 \mathrm{~m}$ in one instance.

While circling at $10,000 \mathrm{ft}$, where the refractive index was quite uniform, it was noticed that a

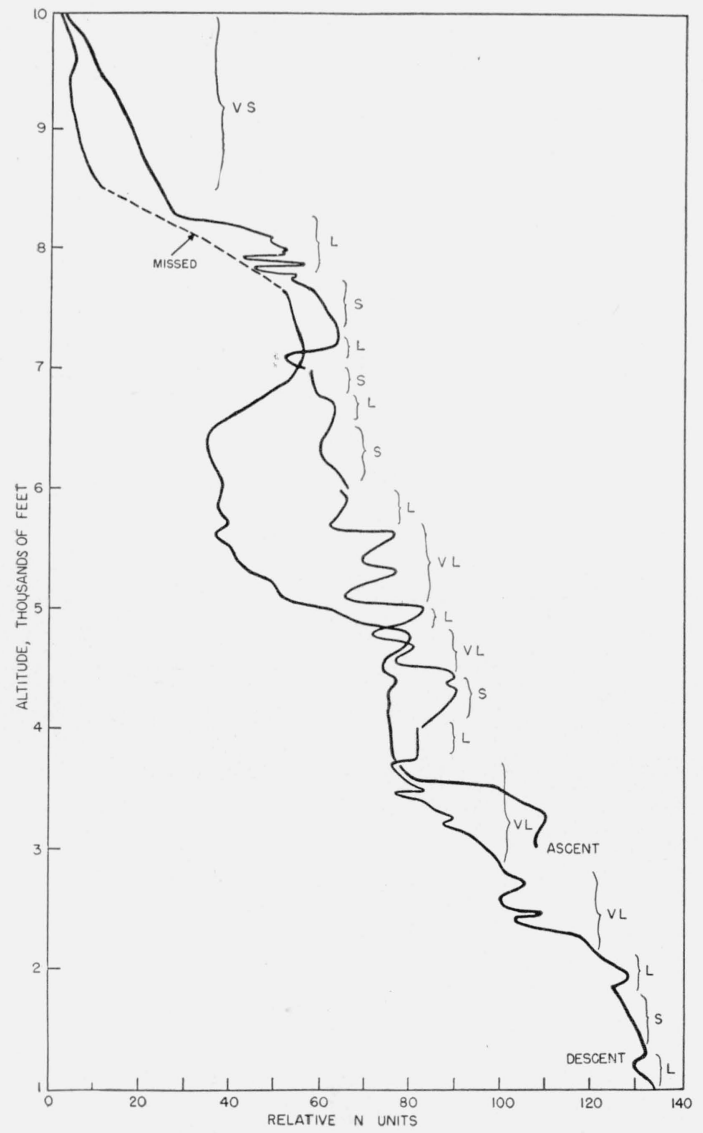

FiguRE 5. A smoothed ascent sounding, and a descent sounding taken about $1 \frac{1}{2}$ hours later.

Breaks in the descent curve occur due to interruption of the descent for horizontal explorations. The adjectives describing the rapid fluctuations (applicable to the descent curve only) represent amplitudes approximately as follows: VS, very small, $0.25 N$ or less; $\mathrm{S}$, small, $0.5 \mathrm{~N}$; L, large, $1.0 \mathrm{~N}$; VL, very large, $2.0 \mathrm{~N}$ or more. definite increase occurred as a nearby cloud was passed. The distance of closest approach to the cloud was 1 or 2 miles.

\subsection{Refractive-Index Profiles}

To obtain the variation of refractive index with height, the original data were smoothed by obtaining visually sucessive 10 -sec averages. Curves plotted from such values are shown in figure 5. Included there are rough estimates of the mean amplitude of those fluctuations less than 5 sec in duration. On comparing these estimated amplitudes with the gradient, one notices the not surprising result that regions of change of gradient are associated with large fluctuation amplitudes.

One of the curves in figure 5 is based on data taken in ascent and the other on data taken in descent about $1 \frac{1}{2} \mathrm{hr}$ later. During this interval the refractive index clearly increased at all levels above $5,000 \mathrm{ft}$. For comparison, refractive-index profiles computed from radiosonde data are shown in figure 6 . These data $^{7}$ were obtained in the vicinity of Silver Hill, Md., in the morning and evening of the day of the flight. The increase in index during this longer interval is somewhat greater than that noted above. This increase as shown by the radiosonde data must have been due almost entirely to changes in watervapor density, as the temperature and pressure profiles scarcely changed.

7 Supplied by the U. S. Weather Bureau.

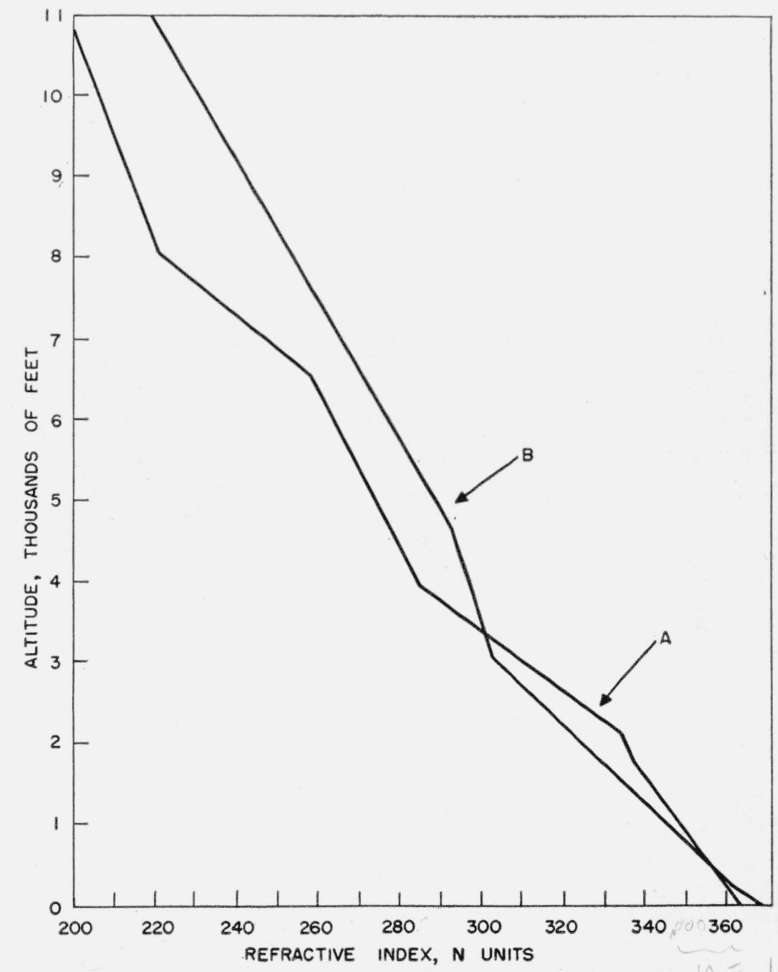

Figure 6. Refractive-index profiles for Washington, D. C., August 19, 1952, calculated from radiosonde ascents. a, $1000 \mathrm{EST} ;$ b, 2200 ETS. 


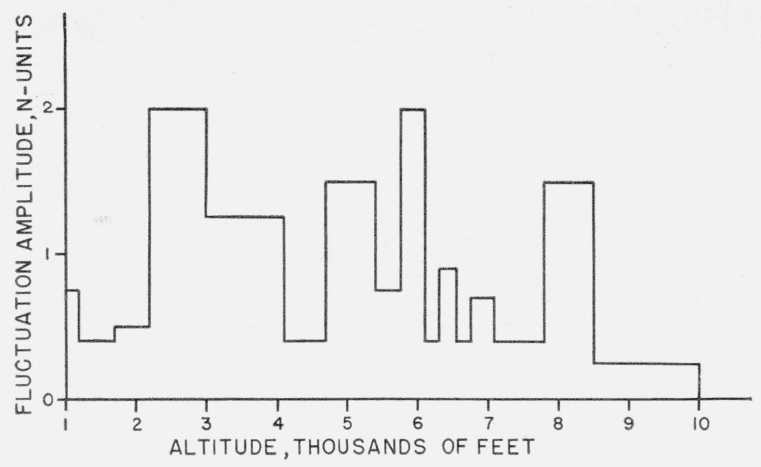

FIgURE 7. Amplitude of fluctuations of medium-sized parcels as a function of altitude

\section{Data Analysis}

This section presents the results of a rough statistical treatment of the data based upon the following considerations. The atmosphere may be regarded as an assembly of air parcels whose refractive-index values differ from one another and in general from the mean value. Within any large parcel there may be smaller parcels of smaller index variations and so on. The refractive-index amplitude of a parcel was taken as the peak positive or negative deviation from the local mean and the extent or size, in the direction of flight, as the interval between consecutive intersections of the record with the local mean. A rough estimate was made of the percentage of time that parcels of various sizes appeared to be present. The duration of the local running mean was adjusted in proportion to the size of the parcels to be analyzed. The results are expected to be roughly related to Fourier amplitudes and periods as might be obtained by usual statistical methods.

The results of the data analysis are summarized in table 2, which shows that both the amplitude and percentage of time present increase with the size of the parcel. In a few cases, where level flights in a given direction were made, sizes greater than the $6,000 \mathrm{~m}$ indicated in table 2 were observed. Indeed, the presence of air parcels some 10 to 30 miles in extent has been detected by aircraft measurements of temperature and vapor pressure $[9,10]$.

TABLe 2. Estimates of extenis and amplitudes of the refractiveindex inhomogeneities (parcels)

\begin{tabular}{|c|c|c|c|}
\hline Altitude & Extent & $\begin{array}{c}\text { A verage } \\
\text { amplitude }\end{array}$ & Time present \\
\hline $\begin{array}{c}f t \\
1,000 \text { to } 8,000\end{array}$ & $\begin{array}{c}m \\
10 \text { to } 20 \\
40 \text { to } 80 \\
100 \text { to } 500 \\
2,000 \text { to } 6,000 \\
10 \text { to } 15 \\
20 \text { to } 30 \\
200 \text { to } 300\end{array}$ & $\begin{array}{l}N \\
0.2 \\
1.0 \\
1.5 \\
4.5 \\
0.04 \\
.1 \\
.25\end{array}$ & $\begin{array}{r}\% \\
40 \\
60 \\
80 \\
100 \\
50 \\
80 \\
80\end{array}$ \\
\hline
\end{tabular}

The 1,000-m range of sizes at altitudes above $8,500 \mathrm{ft}$ were not included in table 2. Variations in the altitude of the aircraft over such distances could have caused the small refractive-index variations observed.

For parcel sizes of the order of several hundred meters, the variation of amplitude with height is shown in figure 7 . In this particular case there is certainly no clear systematic variation. It should be noted that the amplitudes for the region 1,000 to $8,000 \mathrm{ft}$ in table 2 are averaged over the wide variations indicated by figure 7 .

An important finding of this analysis was the fact that the amplitude of the refractive-index inhomogeneities of small extent was extremely small. From the absence of broadening of the trace while the sensitivity was $7 N$ full scale, it was concluded that sizes in the range of 0.5 to $5 \mathrm{~m}$, if present, had amplitudes no greater than $0.04 \mathrm{~N}$. There were some 10 instances in the flight where this more sensitive scale was used. In addition there was an initial test flight (made on August 15), with most of the data recorded at $10,000 \mathrm{ft}$, which also showed the absence of trace broadening within the limits specified above. As for the remainder of the present flight, taken with a full-scale sensitivity of $33 \mathrm{~N}$, from the absence of trace broadening it can only be stated that 5 -m sizes, if present, had amplitudes less than $0.1 \mathrm{~N}$ at all times.

\section{Discussion}

\subsection{Causes of Refractive-Index Fluctuations}

For the mean conditions of temperature, vapor pressure, and total pressure encountered in the flight, the change in refractive index, $\Delta n$, is approximately related to the change in temperature, $\Delta T\left({ }^{\circ} \mathrm{C}\right)$, and to the change in vapor pressure, $\Delta e(\mathrm{~mm} \mathrm{Hg})$ by ${ }^{8}$

$$
\Delta n \times 10^{6}=\Delta N=6 \Delta e-\Delta T .
$$

Rapid pressure fluctuations are too small to influence $\Delta N$. Radiosonde records ${ }^{2}$ taken at Silver Hill, Md., on the day of the flight were examined, and it was found that $\Delta T$ fluctuations for sizes that the radiosonde can best detect-50 to $100 \mathrm{~m}$-were usually less than $0.2 \operatorname{deg} \mathrm{C}$, thus accounting for only a fraction of $\Delta N$ for these sizes (see table 2). It is probable that for other sizes also the changes of index were mainly due to changes of vapor pressure. This view is supported by the measurements of reference [4].

\subsection{Clouds}

The large increases in $N$ observed in the clouds are reasonably accounted for on the basis of changes in water-vapor content. The uprising saturated air in the clouds at a temperature of $13.5^{\circ} \mathrm{C}$ should have a refractive-index value about $70 \mathrm{~N}$ greater than if it were dry. As shown by radiosonde data, the relative humidity outside the cloud at 7,000 ft was about 40 percent. The observed increases of 35 to $40 \mathrm{~N}$ in

\footnotetext{
- 8 This result was obtained from the expression $(n-1) 10^{6}=103.5 P / T+4.97 \times 10^{5}$ e/ $T^{2}$, using representative values of the variables. ( $P$ is the total pressure in $\mathrm{mm} \mathrm{Hg.)}$

9 Provided by the U. S. Weather Bureau. The time constant (4 sec) should
} allow parcels of dimensions (in the vertical direction) of 50 to $100 \mathrm{~m}$ to be detected. 
the clouds are therefore reasonable. The liquid droplets of these clouds would contribute a small amount to the index-less than $1 N$. An artificial effect due to deposition of liquid drops on the cavity walls does not appear likely because of the rapidity of the observed variations. The existence of large amplitude fluctuations within the cumulus cloud may be evidence of the process called entrainment [11], in which surrounding drier air mixes with the uprising saturated air of the cloud.

The index inhomogeneity in the clouds was so great that it was wondered whether appreciable radar return could result. The back-scattering cross section per unit volume is given by $\overline{\Delta n^{2}} / 8 \pi l$ [15] where $l$, the scale of turbulence, is large compared to the radar wavelength. From the data it was estimated that $l$ was of the order $100 \mathrm{~m}$, and $\overline{\Delta n^{2}}$ was $10^{-10}$. These values yield a cross section of $4 \times 10^{-16}$ $\mathrm{cm}^{2} / \mathrm{cm}^{3}$. For $10-\mathrm{cm}$-wavelength radiation, this result is about 100 times larger than that expected due to Rayleigh scattering from rainless clouds ${ }^{10}$ in which the mean drop diameter is $0.001 \mathrm{~cm}$, but even so, it amounts to only a very small scattering cross section capable of detection only at a short rangeof the order of 1 mile.

\subsection{Soundings}

The ascent and descent soundings (fig. 5) differ not only as to the aspect of the coarse gradient but also as to the amount of fine structure. The ascent was made immediately after low-lying stratus clouds were dissipated by the sun's heating and may have taken place before the onset of strong vertical mixing. The subsequent descent shows greater inhomogeneity, such as might have been caused by widespread vertical mixing.

It should be realized that the various changes of gradient in a sounding may be due to three causes: (1) a rather permanent stratification, ${ }^{11}$ (2) a temporary or fluctuating gradient, and (3) an artificial effect that occurs because the angle of ascent is small, thus allowing horizontal gradients to give rise to apparent vertical gradients. The existence of permanent layers can, of course, be confirmed by repeated soundings as was done in connection with the layer boundary at 8,300 ft. The large gradient observed in ascent at $3,500 \mathrm{ft}$ may also have represented a layer boundary, but this was not checked.

\subsection{Index Parcels of Small Size}

In the present work it was found that the fluctuation amplitude associated with an index parcel decreased with the size of the parcel. In fact, the amplitudes of $5-\mathrm{m}$ parcels (and smaller) were found to be negligible. A similar finding was reported by Crain et al. [4], although their observations did not extend to as small a parcel size as observed here.

\footnotetext{
${ }^{10}$ It appears that Friend [12] may have detected rainless clouds with 10 -cm radar.

11 Stable stratifications of water vapor in the atmosphere have been observed by Dobson, Brewer, and Cwilong [13], using an airborne dew-point hygrometer.
}

These results, although of limited scope, lend some support to Megaw's [14] assumption, made in connection with his theory of atmospheric scattering of radio waves, of a (Kolmogoroff) spectrum of parcel sizes terminated at $10 \mathrm{~cm}$ by viscosity on the smallsize end. Booker and Gordon [15], in dealing with radio-wave scattering, used a scale or mean parcel size of $10 \mathrm{~cm}$ with an amplitude of $1 \mathrm{~N}$, but no such parcels were observed in the present experiments.

\section{Conclusions}

Although a limited amount of data was taken, the results served to demonstrate the operation of the instrument and to give some notions about the refractive-index structure of the atmosphere. It was found that the character of the fluctuations changed erratically with position and time. A persistent feature of the two flights was the absence of very rapid fluctuations. Quantitatively expressed, it was found that fluctuations that occurred in distances of from 0.5 to $5 \mathrm{~m}$ had an amplitude less than $0.04 \times 10^{-6}$ in $n$ (or $0.04 N$ ). The larger amplitude fluctuations occurred over distances of the order of $1,000 \mathrm{~m}$, which interestingly enough is in general agreement with the mean scale of turbulence of $300 \mathrm{~m}$ for the atmosphere obtained by Megaw [14] from stellar scintillation data, and with horizontal dimensions of 2,000 to $3,000 \mathrm{~m}$ of some of the parcels observed by Bunker [16].

The measurements described here were made in cooperation with the Naval Research Laboratory and the aircraft was furnished by that laboratory. We express our gratitude for the cooperation extended to us by the members of the Wave Propagation Research Branch, and especially to R. E. Katz, who aided in several phases of the experiment and to H. D. Metke, who piloted the aircraft. A. Hanyok constructed the electronic equipment. We also thank H. Lyons, K. A. Norton, and J. W. Herbstreit for their interest.

\section{References}

[1] M. Katzin, R. W. Bauchman, and W. Binnion, 3- and 9-cm propagation in low ocean ducts, Proc. IRE 35, 891 (1949).

[1a] J. W. Herbstreit, K. A. Norton, P. L. Rice, and G. E. Schafer, Radio wave scattering in tropospheric propagation, IRE Convention Record, part 2, (New York, N. Y., 1953).

[2] W. Miller, Effective earth's radius for radiowave propagation beyond the horizon, J. Appl. Phys. 22, 55 (1951).

[3] E. C. S. Megaw, Waves and fluctuations, J. Inst. Elec. Engrs. (London) 100, 1 (1953).

[4] C. M. Crain, A. P. Deam, and J. R. Gerhardt, Measurement of tropospheric index-of-refraction fluctuations and profiles, Proc. IRE 41, 284 (1953). See also Refractometer measured tropospheric index-of-refraction profiles, I, Univ. of Texas, Elec. Engr. Res. Lab. (Feb. 1953).

[5] G. Birnbaum, A recording microwave refractometer, Rev. Sci. Instr. 21, 169 (1950).

[6] G. Birnbaum, Fluctuations in the refractive index of the atmosphere at microwave frequencies, Phys. Rev. 8\%, 110 (1951). 
[7] G. Birnbaum, H. E. Bussey, and R. R. Larson, The microwave measurement of variations in atmospheric refractive index, Trans. IRE, Prof. Group on antennas and propagation, No. 3, p. 74 (Aug. 1952).

[8] B. S. Lement, B. L. Averbach, and M. Cohen, The dimensional behavior of invar, Trans. Am. Soc. Metals 43, 1072 (1951). See also, Rev. Sci. Instr. 22, 196 (1951).

[9] R. Frith, Meteorological research flight, Meteorol. Mag. \%8, 3 (1951).

[10] P. A. Langwell, Inhomogeneities of turbulence, temperature, and moisture in the West Indies trade wind region, J. Meteorol. 5, 243 (1948).

[11] E. W. Barrell and H. Riehl, Experimental verification of entrainment of air into cumulus clouds, J. Meteorol. 5, 304 (1948).
[12] A. W. Friend, Theory and practice of tropospheric sounding by radar, Proc. IRE 37, 116 (1949).

[13] G. M. B. Dobson, A. W. Brewer, and B. M. Cwilong, Meteorology of the lower atmosphere, Proc. Royal Soc. (London) [A], 185, 144 (1946).

[14] E. C. S. Megaw, Scattering of electromagnetic waves by atmospheric turbulence, Nature 166, 1100 (1950).

[15] H. G. Booker and W. Gordon, A theory of radio scattering in the troposphere, Proc. IRE 38, 401 (1950).

[16] A. F. Bunker, Diffusion, entrainment, and frictional drag associated with non-saturated buoyant air parcels rising through a turbulent air mass, J. Meteorol. 10, $212(1953)$.

Washington, July 1, 1953. 